against the benefit of avoiding slightly delayed diagnosis in a proportion of cases and potential loss to follow-up in a few.

\section{IS THERE A ROLE FOR ROUTINE USE OF THE LEUCOCYTE ESTERASE TEST?}

Marrazzo et al have shown that, in a population screening strategy for chlamydia, the leucocyte esterase test on urine may reduce costs because of a reasonable negative predictive value. However, the positive predictive value of this test in asymptomatic men was only $20.1 \%$. With a sensitivity similar to that of the smear (66.7\% versus $65.3 \%$, respectively) but an inferior specificity $(76.8 \%$ versus $85.5 \%)$, an approach based on the leucocyte esterase test would in fact perform even worse than one based on smears.

\section{CONCLUSION}

It is quite clear that NGU remains a condition that defies a comprehensive explanation. ${ }^{13}$ A urethral smear will continue to remain an integral part of the clinical examination in men presenting with symptoms of urethritis, not least because of its utility in providing an immediate diagnosis of gonorrhoea. Although further research is needed, available evidence does not favour retaining the present practice of physically examining or performing urethral smears in asymptomatic men. It is time that practice was modernised to reflect the availability of sensitive and specific tests for the only serious pathogen known to be a cause of NGU, and time to stop producing "urethral cripples" on the basis of an unreliable and outdated investigation that has already been abandoned in many countries.

Sex Transm Infect 2007:83:79-81.

doi: $10.1136 /$ sti.2006.024653

\section{Authors' affiliations}

M Shahmanesh, K W Radcliffe, Department of Genitourinary Medicine, Whittall Street Clinic, Whittall Street, Birmingham, UK

Correspondence to: Dr K W Radcliffe, Whittall Street Clinic, Whittall Street, Birmingham B4 6DH, UK; Keith.W.Radcliffe@hobtpct.nhs.uk

\section{REFERENCES}

1 Swartz SL, Kraus SJ. Persistent urethral leukocytosis. $J$ Infect Dis 1979;140:614-17.

2 Wilcox JR, Adler MW, Belsey EM. Observer variation in the interpretation of Gram stained urethral smears. Br J Vener Dis 1981:57:134-6.

3 Smith R, Copas AJ, Prince M, et al. Poor sensitivity and consistency of microscopy in the diagnosis of low grade non-gonococcal urethritis. Sex Transm Infect 2003:79:487-90.

4 Anagrius C, Lore B, Jensen JS. Mycoplasma genitalium: prevalence, clinical significance, and transmission. Sex Transm Infect 2005;81:458-62.

5 Falk L, Fredlund H, Jensen JS. Symptomatic urethritis is more prevalent in men infected with Mycoplasma genitalium than with Chlamydia trachomatis. Sex Transm Infect 2004;80:289-93.

6 Iser P, Read TH, Tabrizi S, et al. Symptoms of nongonococcal urethritis in heterosexual men: a case control study. Sex Transm Infect 2005;81:163-5.

7 Janier M, Lassau F, Casin I, et al. Male urethritis with and without discharge: a clinical and microbiologica study. Sex Transm Dis 1995;22:244-52.

8 Leung A, Eastick K, Haddon LE, et al. Mycoplasma genatalium is associated with symptomatic urethritis. Int J STD AIDS 2006;17:285-8.

9 Marrazzo JM, Whittington WL, Celum CL, et al. Urine-based screening for Chlamydia trachomatis in men attending sexually transmitted disease clinics. Sex Transm Dis 2001;28:219-25.

10 Mena L, Wang X, Mroczkowski TF, et al. Mycoplasma genitalium infections in asymptomatic men and men with urethritis attending a sexually transmitted diseases clinic in New Orleans. Clin Infect Dis 2002;35:1 167-73.

11 Schmid G. Evolving strategies for management of the non-gonococcal urethritis syndrome. J Acquir Immune Defic Syndr 1995;274:577-9.

12 Wiggins RC, Holmes $\mathrm{CH}$, Andersson $\mathrm{M}$, et al Quantifying leukocytes in first catch urine provides new insights into our understanding of symptomatic and asymptomatic urethritis. Int J STD AIDS 2006; 17:289-95.

13 Shahmanesh M. Problems with non-gonococcal urethritis. Int J STD AIDS 1994;5:390-9.
14 Chernesky MA, Martin DH, Hook EW, et al. Ability of new APTIMA CT and APTIMA GC assays to detect Chlamydia trachomatis and Neisseria gonorrhoeae in male urine and urethral swabs. J Clin Microbiol 2005:43:127-31.

15 Jensen JS. Mycoplasma genitalium: the aetiological agent of urethritis and other sexually transmitted diseases. J Eur Acad Dermatol Venereol 2004; 18:1-11.

16 Ross JD, Jensen JS, Ross JDC, et al. Mycoplasma genitalium as a sexually transmitted infection: implications for screening, testing, and treatment Sex Transm Infect 2006;82:269-71

17 Lin JS, Jones WE, Yan L, et al. Underdiagnosis of Chlamydia trachomatis infection. Diagnostic limitations in patients with low-level infection. Sex Transm Dis 1992; 119:259-65.

18 Haddow L, Bunn A, Copas AJ, et al. Polymorph count for predicting non-gonococcal urethral infection: a model using Chlamydia trachomatis diagnosed by ligase chain reaction. Sex Transm Infect 2004;80: 198-200.

19 Totten PA, Schwartz MA, Siöström KE, et al Association of Mycoplasma genitalium with nongonococcal urethritis in heterosexual men. $J$ Infect Dis 2001; 183:269-76

20 Bradshaw CS, Tabrizi SN, Read TR, et al. Etiologies of nongonococcal urethritis: bacteria, viruses, and the association with orogenital exposure. J Infect Dis 2006;193:336-45

21 Manavi K, McMillan A, Young H, et al. Genital infection in male partners of women with chlamydial infection. Int J STD AIDS 2006; 17:34-6.

22 Tait IA, Hart CA. Chlamydia trachomatis in nongonococcal urethritis patients and their heterosexual partners: routine testing by polymerase chain reaction. Sex Transm Infect 2002;78:286-8

23 Bhaduri S, De Silva Y. Chlamydial infection in female partners of male patients diagnosed with asymptomatic non-gonococcal urethritis. Int J STD AIDS 2006;17:498.

24 McCathie R, Carlin E. Does partner notification of men with asymptomatic non-gonococcal urethritis identify chlamydia positive women? Sex Transm Infect 2006:82(Supplement 2):A13.

25 Dean GL. Near-patient testing will not improve the control of sexually transmitted infections. Sex Transm Infect 2006;82:509-12.

26 Geisler WM, Yu S, Hook EW III. Chlamydial and gonococcal infection in men without polymorphonuclear leukocytes on Gram stain: implications for diagnostic approach and management. Sex Transm Dis 2005;32:630-4.

27 Horner PJ. Should we still be testing for asymptomatic non-specific urethritis in departments of genitourinary medicine? Int J STD AIDS 2005; 16:273-7.

\title{
Asymptomatic men: should they be tested for urethritis?
}

\section{Paddy Horner}

\section{More research is needed to determine the cost effectiveness of testing for urethritis}

A lthough more evidence has accumulated since questioning the role of testing for urethritis in asymptomatic men in $2002,{ }^{1}$ there is as yet no definitive answer. Men with asymptomatic urethritis have 2-3 times the risk of having Chlamydia trachomatis and/or Mycoplasma genitalium detected compared with those with no urethritis (table 1). I am concerned that abandoning testing for urethritis could do more harm than good in high risk asymptomatic men.

Testing for urethritis in men attending departments of genitourinary medicine has the following purposes.

- To allow immediate treatment of men with $C$ trachomatis and/or $M$ genitalium with an associated reduction in ongoing transmission in the community. ${ }^{23}$ Currently there is no commercial test for $M$ genitalium.

- To identify partners who may be at increased risk of these infections despite the index patient testing negative for $C$ trachomatis and/or $M$ genitalium. ${ }^{24-6}$

- For men at high risk of HIV, it is a potential marker for increased HIV susceptibility and infectivity. ${ }^{2}$ 
Table 1 Estimated risk of having Chlamydia trachomatis and/or Mycoplasma genitalium in high risk young men with and without urethritis (Gram-stained urethral smear with or without first passed urine Gram-stained thread ${ }^{17}$ ), and their partners, depending on clinical findings

\begin{tabular}{|c|c|c|c|c|}
\hline \multicolumn{3}{|c|}{$\begin{array}{l}\text { Clinical findings of index male attending Department of } \\
\text { Genitourinary Medicine }\end{array}$} & \multicolumn{2}{|c|}{$\begin{array}{l}\text { Risk of } C \text { trachomatis and/or } M \\
\text { genitalium }\end{array}$} \\
\hline $\begin{array}{l}\text { Discharge* and/or } \\
\text { dysuria }\end{array}$ & Penile irritation & Urethritis & Index male & Partner(s)† \\
\hline Yes & $+/-$ & Yes & \multirow{6}{*}{$\begin{array}{l}45-55 \%^{5910} 10 \\
15-25 \% \ddagger^{171320} \\
10- \\
20 \% \ddagger^{125781628} \\
10 \%{ }^{157} \\
<10 \% \\
3 \%^{15716}\end{array}$} & $\mathrm{Hight}^{56}$ \\
\hline No & Yes & Yes & & Moderate† \\
\hline No & No & Yes & & $\underset{6828}{\text { Moderate to low } t^{4-}}$ \\
\hline Yes & $+1-$ & No & & Unknown \\
\hline No & Yes & No & & Low \\
\hline No & No & No & & Low \\
\hline
\end{tabular}

*Either as a symptom or clinical sign.

†High, 40-50\%; moderate, 15-25\%; low, $<10 \%$. Assumes that the partner of a man with urethritis who has tested positive for $C$ trachomatis and/or M genitalium has a $66 \%$ risk of also testing positive, ${ }^{529} 30$ and the partner of a man who has tested negative has a 5-25\% risk. ${ }^{4-68} 828$

\#Exact risk difficult to quantify because of variation in definition of "asymptomatic" in clinical studies; see text.

- High negative predictive value (NPV) $(>97 \%)$ for $C$ trachomatis and/or $M$ genitalium in those without urethritis. ${ }^{5}$

\section{ANALYSIS OF CURRENT LITERATURE ON URETHRITIS WITH A UNIFYING HYPOTHESIS ON THE AETIOLOGY}

The literature on urethritis is full of contradictory findings, which make interpretation difficult. I believe that we need to be able to explain these conflicting observations, in order to understand the true value of testing for urethritis in clinical practice. For example (1) Angarius et al detected $C$ trachomatis and/ or $M$ genitalium in only $26 \%$ of men with acute urethritis, whereas Falk et al, Totten et al and Horner et al observed $>45 \% .^{5-10}$ (2) Why do some studies show that urethritis identifies $>80 \%$ of people with $C$ trachomatis (and $M$ genitalium $)^{57811}$ but others do not? ${ }^{1213}$

\section{Possible explanations for conflicting observations}

(1) In some studies the urethral smear was more representative of the urethral inflammatory response than others. This will be related to both the technique of obtaining and preparing the urethral smear and probably how long patients have held their urine (given the long-standing clinical practice of undertaking an early morning smear in symptomatic patients who initially test negative for urethritis). There is no internationally recognised standardised technique for testing for urethritis. There are at least five different methodologies in the literature for diagnosing urethritis, ${ }^{157913}$ and in one recent study patients only had to be symptomatic to be defined as having urethritis! $!^{12}$ In addition, inter-observer and intraobserver error, especially in samples with low-grade inflammation (5-20 polymorphonuclear leucocytes/ high power field), may also play a role. ${ }^{13-15}$

(2) The populations studied varied in degree of risk (behaviour and age) for having a sexually transmitted infection ( $C$ trachomatis detection is associated with a younger age $\left.{ }^{16}\right)$.

(3) Some studies do not distinguish men with penile irritation/discomfort from those with dysuria or discharge, as the former are at decreased risk of asexually transmitted infection (STI). ${ }^{1713}$

(4) There is confusion about the term "asymptomatic" which is often assumed to mean that the person does not have a urethral discharge. About $10 \%$ of men will have a discharge on examination which is not reported as a symptom. ${ }^{7} M$ genitalium is associated with urethral discharge. $^{5}$

\section{Other causes of urethritis}

Partner studies, although limited, suggest that up to $25 \%$ of patients with microorganism-negative acute urethritis may have a partner infected with either $C$ trachomatis or $M$ genitalium. ${ }^{2-6}$ Although ureaplasmas can cause urethritis, their exact role remains unclear and probably only account for $\sim 5-15 \%$ of acute urethritis. ${ }^{17}{ }^{18}$ The importance of Trichomonas vaginalis probably depends on the prevalence in the local population. ${ }^{17}$ Herpes, adenovirus and urinary tract infections probably account for $<5 \%$ each. ${ }^{17}{ }^{19}$ What causes the remainder is not known. It remains to be shown whether another major pathogen will be identified.

\section{Unifying hypothesis}

My group's work suggests that the risk of an STI increases as the degree of inflammation increases and that the symptoms, discharge, dysuria and/or an observable discharge, are surrogate markers for the degree of inflammation. ${ }^{20}$ Or looked at the other way round, it implies that urethritis can have non-pathogenic causes-for example, bacterial vagino$\operatorname{sis}^{21}$-and this is more likely in men with low-grade urethritis. This challenges the idea of having a simple cut-off and labelling all those with $<5$ polymorphonuclear cells per high power field as at low risk of having a $C$ trachomatis and/or $M$ genitalium infection, and all those with $\geqslant 5$ polymorphonuclear cells per high power field as at high risk. Thus men with asymptomatic urethritis are more likely to have a low-grade urethritis with a lower risk of being caused by an STI than if they were symptomatic, but at increased risk compared with asymptomatic men without urethritis. This reduced risk also probably applies to their partner(s) testing positive for an STI even if they test microorganism negative, although the evidence is conflicting. ${ }^{4}$

To fully assess a patient's risk (and that of their partner(s)) of having either infection, one needs to consider, age, sexual behaviour, clinical presentation, and the results of testing for urethritis. Table 1 details the estimated risks according to clinical findings based on published evidence currently available.

\section{IS THE GRAM-STAINED URETHRAL SMEAR THE BEST METHOD FOR DETECTING URETHRITIS?}

As hypothesised in (1) above, it is likely that a Gram-stained urethral smear is more reliable in some centres than others in detecting urethritis. The technique described by Wiggins et al, ${ }^{20}$ although too complex for routine clinical practice, offers the opportunity of investigating how best to obtain, and evaluate, a specimen that is representative of the urethral inflammatory response. This would provide an objective evidence base for not only helping to interpret studies but also to develop an international standard for future research which can then be translated into clinical practice.

\section{Potential role of leucocyte esterase} testing in asymptomatic men

Given the variability of a Gram-stained urethral smear in detecting urethritis (see above), especially at low grades, ${ }^{15}$ are there other ways of testing for urethritis? Although the leucocyte esterase test has 
insufficient sensitivity to detect urethritis, ${ }^{17}$ Marrazzo et $a l^{16}$ observed in a study of over 1500 asymptomatic men using a nucleic acid amplification technique (NAAT) that the leucocyte esterase test had a positive predictive value (PPV) of $13 \%$ and an NPV of $97.7 \%$ for the detection of $C$ trachomatis compared with $20 \%$ and $97.8 \%$ for the Gram-stained urethral smear. Horner and TaylorRobinson ${ }^{22}$ have recently argued that the leucocyte esterase test, which is both inexpensive and non-invasive, offers an interim, evidence-based, solution to the issue of whether asymptomatic men attending departments of genitourinary medicine should be screened for the presence of urethral inflammation.

\section{CLINICAL ROLE OF TESTING FOR URETHRITIS IN ASYMPTOMATIC MEN}

The questions are therefore ( 1 ) is this of benefit to the patient and the public health and (2) could testing do more harm than good (to be addressed by Dr Shahmanesh in accompanying editorial)?

If we consider rationalising/minimising testing for asymptomatic men, there are a number of options available.

(1) Use NAATs for $C$ trachomatis and Neisseria gonorrhoeae on a first catch urine specimen only ${ }^{22}$ with all gonococcal-positives confirmed by culture. It is well recognised that some men with $N$ gonorrhoeae are asymptomatic ${ }^{2}$ and would be missed if the microorganism was not tested for, and Horner and Taylor-Robinson ${ }^{22}$ advocate testing for both, but acknowledge the increased risk of falsepositives not only because it is a low-prevalence population ${ }^{23}$ but also because some NAATs can detect commensal Neisseria species. ${ }^{24-26}$

(2) As for (1) but examine and only undertake a Gram-stained urethral smear for those with a discharge.

(3) As for (2) but include a leucocyte esterase test on those without a discharge.

The disadvantages of option (1) are:

- Failure to identify about $10 \%$ of men who are unaware of their urethral discharge. This group and their partners are at high risk of an STI, in particular $M$ genitalium (table 1$)^{257}$

- May result in other pathology being missed in some men

- Misses the opportunity of the intimacy of a genital examination to help enable the patients to disclose concerns of a deeply personal nature
- A group of men and their partners(s) with 10-20\% (urethritis positive) risk of $C$ trachomatis and/or $M$ genitalium as per table 1 will be missed

Option (2) would address the first three of these points, and option (3) all of them. Although the leucocyte esterase test has a lower PPV than a Gram-stained urethral smear (see above), it still has a high NPV (>97.5\%) — that is, those with a negative leucocyte esterase test are at a substantially lower risk of having an STI. ${ }^{16}$

Option (3) was introduced in 2006 in Bristol, with the examination being optional for the patient. This strategy is likely to be most cost effective in: (1) younger men $(<25$ years old) with high risk behaviour in whom $(a)$ the PPV for an STI will be highest $(23 \%$ for $C$ trachomatis $)^{16}$ and $(b)$ the risk of transmitting an STI to a new sexual partner before microbiological results are available is greatest ${ }^{327}$; (2) men at increased risk of HIV, as inflammation increases both susceptibility and infectivity. ${ }^{2}$ It is also likely to be preferred by patients who have had a casual relationship within a regular relationship, because of the improved NPV associated with a failure to detect urethritis.

\section{CONCLUSION}

As genitourinary physicians, we need to decide whether it is an effective use of our resources to make a complete assessment of a man's risk of having or being recently exposed to an STI. In order to do this, I believe that we need to consider, age, sexual behaviour, clinical presentation, and the results of testing for urethritis. A complete risk assessment potentially makes the consultation more complex, but need not be significantly more time consuming during the initial assessment, if we use non-invasive testing for both $N$ gonorrhoeae and $C$ trachomatis and urethritis using a NAAT and leucocyte esterase test respectively. ${ }^{22}$ Given the increasing pressure to achieve the government's 48hour access target for departments of genitourinary medicine ${ }^{31}$ and the fact that better utilisation of resources must be part of the solution, this would seem a reasonable evidence-based compromise in the debate about testing for urethritis in asymptomatic men. ${ }^{22}$ Clearly more research, with standardised methodology, to allow rapid translation of findings into clinical practice, is urgently required on the aetiology, diagnosis, acceptability and cost effectiveness of testing for urethritis in departments of genitourinary medicine.

Sex Transm Infect 2007;83:81-84.

doi: $10.1136 /$ sti.2006.024414
Correspondence to: Dr Horner, the Milne Centre, Bristol Royal Infirmary, Lower Maudlin Street Bristol BS2 8HW, UK; paddy.horner@bristol. ac.uk

Dr P J Horner would like to thank the Jefferiss Trust for its support and Dr Judith Berry for her helpful comments on the manuscript.

\section{REFERENCES}

1 Horner PJ, Thomas B, Gilroy CB, et al. Do all men attending departments of genitourinary medicine need to be screened for non-gonococcal urethritis? Int J STD AIDS 2002; 13:667-73.

2 Horner PJ. Should we still be testing for asymptomatic non-specific urethritis in departments of genitourinary medicine? Int J STD AIDS 2005; 16:273-7.

3 Vickerman $P$, Watts $C$, Alary $M$, et al. Sensitivity requirements for the point of care diagnosis of Chlamydia trachomatis and Neisseria gonorrhoeae in women. Sex Transm Infect 2003;79:363-7.

4 Bhaduri S, De SY. Chlamydial infection in female partners of male patients diagnosed with asymptomatic non-gonococcal urethritis. Int J STD AIDS 2006;17:498.

5 Falk L, Fredlund $\mathrm{H}$, Jensen JS. Symptomatic urethritis is more prevalent in men infected with Mycoplasma genitalium than with Chlamydia trachomatis. Sex Transm Infect 2004;80:289-93.

6 Manavi K, McMillan A, Young H. Non-chlamydial non-gonococcal urethritis or undiagnosed chlamydial urethritis? Int J STD AIDS 2006; 17:296-8.

7 Leung A, Eastick K, Haddon L, et al. Mycoplasma genitalium is associated with symptomatic urethritis Int J STD AIDS 2006;17:285-8.

8 Anagrius C, Lore B, Jensen JS. Mycoplasma genitalium: prevalence, clinical significance, and transmission. Sex Transm Infect 2005;81:458-62.

9 Horner PJ, Gilroy CB, Thomas BJ, et al. Association of Mycoplasma genitalium with acute nongonococcal urethritis. Lancet 1993;342:582-5.

10 Totten PA, Schwartz MA, Sjostrom KE, et al. Association of Mycoplasma genitalium with nongonococcal urethritis in heterosexual men. $J$ Infect Dis 2001;183:269-76.

11 Geisler WMM, Yu S, Hook EW III. Chlamydial and gonococcal infection in men without polymorphonuclear leukocytes on gram stain: implications for diagnostic approach and management. Sex Transm Dis 2005;32:630-4

12 Bradshaw CS, Tabrizi SN, Read TRH, et al. Etiologies of nongonococcal urethritis: bacteria, viruses, and the association with orogenital exposure. J Infect Dis 2006;193:336-45

13 Haddow L, Bunn A, Copas AJ, et al. Polymorph count for predicting non-gonococcal urethral infection: a model using Chlamydia trachomatis diagnosed by ligase chain reaction. Sex Transm Infect 2004;80: 198-200.

14 Willcox JR, Adler MW, Belsey EM. Observer variation in the interpretation of Gram-stained urethral smears: implications for the diagnosis of nonspecific urethritis. Br J Vener Dis 1981;57:134-6.

15 Smith R, Copas AJ, Prince M, et al. Poor sensitivity and consistency of microscopy in the diagnosis of low grade non-gonococcal urethritis. Sex Transm Infect 2003;79:487-90.

16 Marrazzo JM, Whittington WL, Celum CL, et al. Urine-based screening for Chlamydia trachomatis in men attending sexually transmitted disease clinics. Sex Transm Dis 2001;28:219-25.

17 Clinical Effectiveness Group (Bristish Association of Sexual Health, HIV). National guideline for the management of non-gonococcal urethritis. http:// www bashh org/guidelines/2002/ngu_0901c pdf 2001 Augusthttp://www.bashh.org/ guidelines.asp (accessed 6 Mar 2007).

18 Horner P, Thomas B, Gilroy CB, et al. Role of Mycoplasma genitalium and Ureaplasma urealyticum in acute and chronic nongonococcal urethritis. Clin Infect Dis 2001;32:995-1003.

19 Leung A, Taylor S, Smith A, et al. Urinary tract infection in patients with acute non-gonococcal urethritis. Int J STD AIDS 2002;13:801-4.

20 Wiggins R, Holmes C, Andersson M, et al. Quantifying leukocytes in first-catch urine samples 
can provide new insights to our understanding of symptomatic and asymptomatic urethritis. Int J STD AIDS 2006:17:289-95.

21 Keane FE, Thomas BJ, Whitaker L, et al. An association between non-gonococcal urethritis and bacterial vaginosis and the implications for patients and their sexual partners. Genitourin Med 1997:73:373-7.

22 Horner PJ, Taylor-Robinson D. A role for leucocyte esterase testing in conjunction with non-invasive screening using nucleic acid amplification tests for asymptomatic men attending departments of Genitourinary Medicine. Int J STD AIDS 2007; 18:73-4

23 Zenilman JM, Miller WC, Gaydos C, et al. LCR testing for gonorrhoea and chlamydia in population surveys and other screenings of low prevalence populations: coping with decreased positive predictive value. Sex Transm Infect 2003;79:94-7

24 Palmer HM, Mallinson $\mathrm{H}$, Wood RL, et al. Evaluation of the specificities of five DNA amplification methods for the detection of Neisseria gonorrhoeae. J Clin Microbiol 2003;41:835-7.

25 Akduman D Ehret JM Messina K etal. Evaluation of strand displacement amplification assay (BD ProbeTecSDA) for detection of Neisseria gonorrhoeae in urine specimens. J Clin Microbiol, 2002;40, 281-3.

26 Diemert DJ, Libman MD, Lebel P. Confirmation by $16 \mathrm{~S}$ rRNA PCR of the COBAS AMPLICOR CT/NG test for diagnosis of Neisseria gonorrhoeae infection in a low-prevalence population. J Clin Microbiol 2002;40:4056-9.

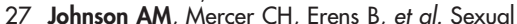
behaviour in Britain: partnerships, practices, and HIV risk behaviours. Lancet 2001;358: 1835-42.
28 Tait IA, Hart CA. Chlamydia trachomatis in nongonococcal urethritis patients and their heterosexual partners: routine testing by polymerase chain reaction. Sex Transm Infect 2002:78:286-8.

29 Quinn TC, Gaydos C, Shepherd M, et al. Epidemiologic and microbiologic correlates of Chlamydia trachomatis infection in sexual partnerships. JAMA 1996:276:1737-42.

30 Clad A, Prillwitz J, Hintz KC, et al. Discordant prevalence of Chlamydia trachomatis in asymptomatic couples screened using urine ligase chain reaction. Eur J Clin Microbiol Infect Dis $2001 ; 20: 324-8$.

31 Department of Health. A health promoting NHS transforming sexual health services. In: Choosing health:making healthy choices easier.http:// www.dh.gov.uk/assetRoot/04/09/47/64/ 04094764.pdf, pp 145-7 (accessed 6 Mar 2007)

\section{BMJ Clinical Evidence-Call for contributors}

BMJ Clinical Evidence is a continuously updated evidence-based journal available worldwide on the internet which publishes commissioned systematic reviews. BMJ Clinical Evidence needs to recruit new contributors. Contributors are healthcare professionals or epidemiologists with experience in evidence-based medicine, with the ability to write in a concise and structured way and relevant clinical expertise.

Areas for which we are currently seeking contributors:

- Secondary prevention of ischaemic cardiac events

- Acute myocardial infarction

- MRSA (treatment)

- Bacterial conjunctivitis

However, we are always looking for contributors, so do not let this list discourage you

Being a contributor involves:

- Selecting from a validated, screened search (performed by in-house Information Specialists) valid studies for inclusion.

- Documenting your decisions about which studies to include on an inclusion and exclusion form, which we will publish.

- Writing the text to a highly structured template (about 1500-3000 words), using evidence from the final studies chosen, within 8-10 weeks of receiving the literature search.

- Working with BMJ Clinical Evidence editors to ensure that the final text meets quality and style standards.

- Updating the text every 12 months using any new, sound evidence that becomes available. The BMJ Clinical Evidence in-house team will conduct the searches for contributors; your task is to filter out high quality studies and incorporate them into the existing text.

- To expand the review to include a new question about once every 12 months.

In return, contributors will see their work published in a highly-rewarded peer-reviewed international medical journal. They also receive a small honorarium for their efforts.

If you would like to become a contributor for BMJ Clinical Evidence or require more information about what this involves please send your contact details and a copy of your CV, clearly stating the clinical area you are interested in, to CECommissioning@bmigroup.com.

\section{Call for peer reviewers}

BMJ Clinical Evidence also needs to recruit new peer reviewers specifically with an interest in the clinical areas stated above, and also others related to general practice. Peer reviewers are healthcare professionals or epidemiologists with experience in evidence-based medicine. As a peer reviewer you would be asked for your views on the clinical relevance, validity and accessibility of specific reviews within the journal, and their usefulness to the intended audience (international generalists and healthcare professionals, possibly with limited statistical knowledge). Reviews are usually 1500-3000 words in length and we would ask you to review between 2-5 systematic reviews per year. The peer review process takes place throughout the year, and our turnaround time for each review is 10-14 days. In return peer reviewers receive free access to BMJ Clinical Evidence for 3 months for each review.

If you are interested in becoming a peer reviewer for BMJ Clinical Evidence, please complete the peer review questionnaire at www.clinicalevidence.com/ceweb/contribute/peerreviewer.jsp 